\title{
HISTORIA Y ARQUEOLOGÍA \\ EN LA IGLESIA DE AMADORES
}

\section{Claudio Caraffini*; Emilio Villafañez*; Ezequiel Fonseca**; Cristian Melián ${ }^{* * *}$ y Hugo Puentes***}

\begin{abstract}
Resumen
La vieja Capilla de Amadores ubicada en el Departamento Paclín, provincia de Catamarca, tiene una historia por demás particular, puesto que a lo largo de las décadas fue interpretada y re-interpretada desde diversos puntos de vistas (sean estos políticos, sociales o religiosos). Diversas crónicas periodísticas la destacan como una construcción jesuita, algo que se consolidó con la presentación y posterior aprobación de una ley de patrimonialización por su supuesta pertenencia a la congregación de Jesús. Numerosos trabajos que estamos llevando adelante desde hace más de una década, nos muestran que la iglesia en cuestión es una construcción muy posterior. Fueron extensas búsquedas bibliográficas junto a numerosas excavaciones arqueológicas las que nos permitieron demostrar lo antes dicho. Así este trabajo quiere avanzar sobre la historia de las pulsaciones de una capilla que tuvo un fuerte vínculo con la localidad donde se asentó, puesto que ambas siguieron la misma suerte.
\end{abstract}

Palabras clave: Iglesia, documentos, Amadores, arquitectura.

\begin{abstract}
The old Chapel Amadores located in the Paclín department, province of Catamarca has a history other particular since over the decades was interpreted and reinterpreted from different points of view (Be they political, social or religious). Various newspaper reports the stand as a Jesuit building, which was consolidated with the submission and approval of a law patrimonialization for their alleged membership in the congregation of Jesus. Numerous studies we are carrying out for over a decade, we show that the church in question is a much later construction. They were extensive literature searches with numerous archaeological excavations that allowed us to demonstrate what has been said. So this paper wants to advance on the history of the pulsations of a chapel that had a strong bond with the town where he settled, since both followed the same fate.
\end{abstract}

Keywords: Church, documents, lovers, architecture.

\footnotetext{
* Escuela de Arqueología, Universidad Nacional de Catamarca.

** Departamentos de Historia, Facultad de Humanidades, Universidad Nacional de Catamarca.

**** Consejo Nacional de Investigaciones Científicas y Técnicas, CONICET.
} 


\section{Introducción}

Nuestra propuesta de trabajo parte de desarrollar una investigación desde la Arqueología Histórica teniendo como objetivo comprender el contexto histórico y cómo fueron los procedimientos de creación, ocupación y transformación de la Capilla de Amadores. En la actualidad se encuentra en ruinas y la población existente la considera como perteneciente a la orden jesuítica, a tal punto que fue declarada monumento histórico provincial ${ }^{1}$. Para poder avanzar sobre la historia de esta Capilla o lo que nosotros consideramos sus pulsaciones, contrariamente a lo que se cree, el análisis de documentación existente en archivos y bibliotecas de Catamarca nos develó que su construcción se realizó en el año 1869 y que fue dedicada a Nuestra Señora de La Candelaria y se impulsó cuando se dio el desmembramiento del antiguo curato y departamento de Piedra Blanca en tres nuevos departamentos ${ }^{2}$. Sobre esta situación es que intentamos contribuir mediante la información proporcionada por fuentes documentales, fotografías periodistas de archivos históricos y excavaciones arqueológicas.

La arqueología histórica, como marco teórico, nos permitió tomar nuestra propuesta de trabajo desde dos perspectivas la primera de ellas se relaciona a la cultura material, tomando a la construcción como indicador espacial, puesto que una fuente de información sobre la vida eclesiástica y rural en esta localidad del Valle de Paclín. A su vez, los restos artefactuales obtenidos en las excavaciones nos brindarán datos adicionales a lo expuesto. La segunda perspectiva, son los datos históricos que existen para nuestra área de estudio, tomamos así las fuentes documentales del Archivo del Obispado de Catamarca y el Archivo Histórico de Catamarca.

La investigación desarrollada en este trabajo se ha estructurado sobre la base de considerar a la edificación como una unidad de análisis, para lo cual la metodología que se utilizó para la consecución de nuestro objetivo involucró dos grandes etapas, a saber:

La primera comprendió el relevamiento documental, a través de la búsqueda de información bibliográfica que nos brinde un cuadro de referencia y contextualización de la Capilla para el siglo XIX, sumando a ello una indagación de archivos en bibliotecas municipales y provinciales, el Archivo Histórico Provincial y por último el Obispado de Catamarca.

La segunda etapa consistió en diversos trabajos de campo llevados a cabo en la estructura arquitectónica mencionada, para luego realizar el análisis e interpretación de los materiales recuperados por excavaciones, se realizaron sondeos estratigráficos con el objetivo de identificar cada estrato, siguiendo la técnica de decapage para lo cual se realizaron sondeos dirigidos en diversos sectores al interior y exterior de las estructuras.

\section{EI Valle de Paclín en el siglo XIX}

El departamento Paclín, limita al norte con la provincia de Tucumán, al oeste con los departamentos de Santa Rosa y de El Alto, al sur con el departamento 
de Valle Viejo y al oeste con los de Ambato y Fray Mamerto Esquiú. La serranía de El Alto o Ancasti al este y las de Gracián al oeste, estas últimas encierran el valle o cañón de Paclín, surcado por el río homónimo que corre en dirección nortesur (Figura 1).

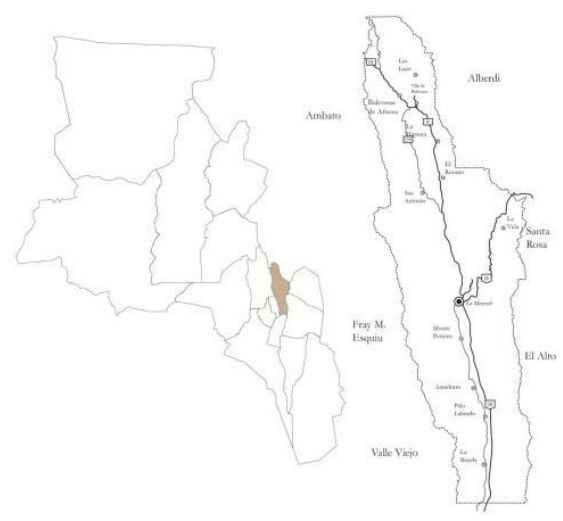

Figura 1: Ubicación geográfica del Departamento Paclín y la localidad de Amadores, en la Provincia de Catamarca.

La otrora pujante localidad de Amadores fue a mediados del siglo XIX la localidad más progresista del valle de Paclín y asiento de una población que vivió en torno a la extracción de productos primarios naturales que se dieron en el monte, la extracción de maderas para ebanistería en la ciudad de Catamarca y la elaboración de tejidos basados en la lana de llamas y vicuñas como así también del algodón que se daba con éxito en toda la región, siendo este un producto muy apreciado por su excelente calidad. La introducción de mercaderías de ultramar que se aceleró luego de la batalla de Caseros produjo en la región una reprimarización de la economía, a tal punto que a finales del siglo los algodoneros estaban al borde de la desaparición siendo sustituidos por el monocultivo de tabaco, nueva forma de riqueza que genero poca mano de obra en una población que estuvo compuesta en su mayoría por peones pobres y sin tierra quienes fueron los que generaron la riqueza económica de la región y que era acaparada por una minoría letrada, dueña de la tierra que manejaba los recursos naturales, humanos y simbólicos (Caraffini 2014, Caraffini et. al. 2014).

Ya en el año de 1869 se crean por ley N96 los departamentos de Pomán, Ambato y Paclín, estos dos últimos dados de la disgregación del departamento Piedra Blanca. En el año 1875, y gracias a la Ley N$^{\circ} 277$, se funda la localidad de la Villa de La Merced que con el tiempo pasará a ser cabecera del nuevo departamento. Este punto es de vital importancia para la esfera social, pues hay una reorganización en todo el aparato productivo social y político de la región.

La estratificación social en el período republicano cambia de modalidad respecto del antiguo orden colonial, donde categorías como negros e indios (propias del antiguo virreinato) son eliminadas para dar paso a una nueva modalidad, "Argentino" (Caraffini et. al 2013). La población de la provincia en general y del 
área de estudio en particular sufrió un largo proceso de mestizaje entre el negro, el indio y el español, dando como resultado la población criolla, particularmente el departamento Paclín, según el segundo censo nacional efectuado en 1895 constaba de 3.306 habitantes.

Las últimas décadas del siglo XIX se caracterizó por la hegemonía liberal y la incorporación del país al sistema capitalista global, que de alguna manera afectó las condiciones de vida de la provincia. En lo que respecta a la industria del algodón de Catamarca, a pesar de la excelencia de la materia prima que se daba en la provincia, ha decaído su industria y su cultivo produciendo cambios notables en las poblaciones a lo largo del tiempo, pues la desaparición de industrias y el reemplazo de cultivos tiene sus consecuencias en las poblaciones que trabajan y viven de esas producciones, alterando en décadas el desarrollo económico y humano de la región. (Poucel, 1864; Alvero, 2007)

Estas transformaciones económicas tuvieron repercusiones profundas en los distintos sectores provinciales, y también hacia el interior de los sectores sociales que componen una sociedad, pues como expresamos anteriormente, las industrias que se habían generado en base al algodón fueron un factor de importancia en la economía del valle a mediados del siglo XIX. Las provincias vecinas, sufrieron también procesos similares. (Bazán 1995)

Particularmente el valle de Paclín fue a partir de la creación del departamento homónimo, un reacondicionador de la esfera socioeconómica, con un fuerte sesgo dado por las elites locales que dirigían políticamente el recientemente creado departamento y su nueva cabecera local, la localidad de La Merced.

\section{La Capilla de Amadores desde los documentos}

Su construcción surgió como una necesidad de la población que debía trasladarse hacia la única capilla existente hasta el momento en el valle de Paclín a una distancia de $12 \mathrm{~km}$ al norte de Amadores. Varias cartas mencionan los pedidos de la comunidad a través de sus "principales vecinos" e incluso del sacerdote pidiendo a las autoridades políticas de la provincia y del Obispado de Salta ${ }^{3}$ para que se deje sin efecto la otra capilla por las dificultades que acarrea a la población trasladarse en ayunas a presenciar los oficios religiosos, teniendo Amadores un edificio casi terminado que ofrece todas las comodidades para el culto (Padilla 1885, Segura 1885) (Figura 2).

Se pudo constatar a través del análisis de documentos que la bendición de la parroquia aconteció el 24 de enero de 1883 a las 17 horas, asistiendo fieles de todo el valle, como así también pobladores del sur de la provincia de Tucumán. Según una carta fechada el 8 de febrero de 1883 y publicada en un diario local de la época ${ }^{4}$ se detalla que para la inauguración se realizó una "modesta pero simpática fiesta" que fue la que se llevó adelante con motivo de la bendición y oficialización del edificio como templo religioso de la comunidad local. En la carta, se hace alusión de los sacerdotes que fueron invitados a la celebración, entre ellos el presbítero Oviedo, el R.P. Fray Francisco Machado, el ayudante del vicario foráneo 
presbítero Francisco Brizuela y el sacerdote a cargo del curato de Paclín presbítero José M. Salas. También se hace mención de las "principales" familias del lugar y de poblaciones vecinas como Santa Cruz, La Cocha (Tucumán) Piedra Blanca y Monte Potrero que asistieron al evento. Finalizada la ceremonia ...la madrina, amable i simpática como siempre hizo invitar a los sacerdotes, al padrino i a varios señores a casa del señor Rodríguez a beber un vaso de cerveza... luego se dio inicio a un discurso en el cual se destaca que el sacerdote José Salas fue el "más infatigable obrero de este templo" y también a "la comisión directiva del trabajo de la iglesia, como así mismo, a todas las personas caritativas i piadosas que han dado una limosna para esta obra". Al final ya cuando dio la noche en la población de Amadores "hubo música en la plaza i el juego del caballito i la negra" (Diario El Creyente 6 de marzo de 1883: 14).

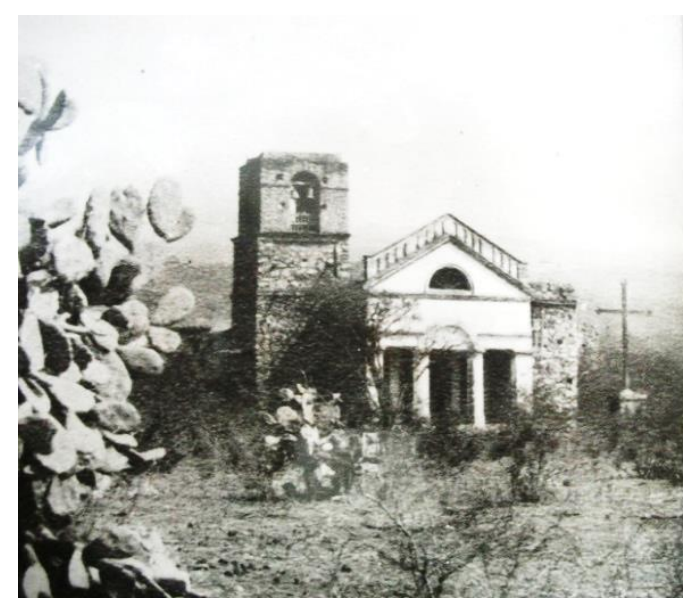

Figura 2: La capilla de Amadores aproximadamente a finales del siglo XIX. Sosa Gallardo (1969).

La primera misa en el nuevo templo se realiza al día siguiente de la bendición (25 de enero de 1883) y fue:

... celebrada por el R.P. Machado i como diáconos los presbíteros Salas $i$ Brizuela. La concurrencia ha sido tan numerosa como no se esperaba: la nave de la iglesia, las dos sacristías, el coro el atrio i el corredor estaban completamente llenos de jente. El presbítero Oviedo subió al pulpito i predicó un sermón que se recomienda por sí mismo... (El Creyente 6 de marzo de 1883:14)

Al final de la carta se hace mención que el:

...cura Salas invito a la concurrencia a su casa en donde se le sirvió con chocolate. Por la tarde hubo corrida de sortija, rompecabezas, carreras; por la noche una concurrida i entusiasta tertulia de baile en casa de la senora Benita Montenegro; en una palabra hubo fiestas. Los vecinos de Amadores están sumamente contentos con la colocación de su templo por 
ser la coronación de sus esfuerzos ;bien por ellos i por el infatigable Sr. Cura Salas!... (El Creyente 6 de marzo de 1883:15)

El siguiente documento que analizamos data del año $1885^{5}$; y en él se vislumbran algunos datos, también sumamente interesantes:

Nombre del templo Ntra. Sra. de "La Candelaria".

Parroquia de Paclín, Localidad Amadores. Provincia de Catamarca.

Se encuentra a cargo del Cura Párroco Pbro. José Torres Escandell, de nacionalidad española.

El edificio representa un valor aproximado de $\$ \mathrm{~m} / \mathrm{n}$ ocho mil. Se ha construido con recursos del finado Cura José Manuel Salas y suscripción popular, sobre el terreno que ocupa de metros ocho de frente por veinte y uno de fondo del interior. De luz tiene seis de frente por diez y siete de fondo. Además la sacristía tiene cinco metros con ochenta centímetros de frente por cuatro de fondo (Archivo del Obispado Catamarca- Carpeta de Paclín 1885: 84).

El documento nos ofrece en particular el nombre del templo, como así también sus medidas, además de mencionar a uno de sus impulsores en la construcción. Así mismo, menciona el sacerdote Salas, Amadores es el lugar en donde estaba concentrado el eje económico de la zona y el lugar de asiento de los vecinos (principales) propietarios, los peones e inquilinos y del cura párroco que oficiaba las misas en Paclín. No debemos olvidar que además se menciona a Amadores como la población más importante del departamento por el número de habitantes, su riqueza y su ilustración. Este último punto es de central importancia para comprender la dinámica histórica que se ha dado en el valle en general y de la localidad en particular.

Otra carta que enviara también el mismo cura párroco Torres Escandell al secretario obispo de Catamarca, Aníbal Villagra en la cual alega que hacia 1920 se le realizaran algunas refacciones al edificio donde además se cuenta que se trasladaran tejas y tejuelas de la iglesia de Paclín Viejo para economizar los gastos de refacción (Villafañez et al. 2011).

\section{La Capilla de Amadores desde la arqueología}

Los datos obtenidos desde las fuentes históricas son sumamente importantes pues lo contrastamos a continuación con las investigaciones arqueológicas que llevamos en la capilla. Estructuralmente la antigua Capilla de Amadores presenta una planta rectangular, a la que se adosan cuatro estructuras. Para el aparejo de las paredes se utilizaron diferentes tipos de materiales: piedra, ladrillo y adobe (Figura $3)$.

El principal material empleado fue roca metamórfica local, la cual se dispuso siguiendo hiladas más o menos regulares pero sinuosas, dejando las superfi- 
cies externas regulares con ancho de muros de $0,60 \mathrm{~m}$. Sobre los muros de roca se apoya uno de adobe, que es utilizado para dar los desniveles del techo; la altura de este muro varía según los desniveles que se dan. En relación a las rocas varían en tamaño $(0,25$ a $0,40 \mathrm{~m})$ estando muchas de ellas canteadas. La argamasa que cohesiona a los mampuestos es de barro, sin otro tipo de aditamento, para las primeras etapas constructivas; a continuación se utilizó una argamasa abundante en cal y áridos, para unir los mampuestos cocidos. Los cimientos son de roca metamórfica local y tienen un ancho de $1 \mathrm{~m}$ con una profundidad aproximada de $0,80 \mathrm{~m}$, los cuales apoyan sobre la roca natural sin mediar soluciones de continuidad que funcione como zanja de cimentación. El edificio consta de seis espacios que hemos denominado con números romanos (Tabla $\mathrm{N}^{\circ} 1$ ).

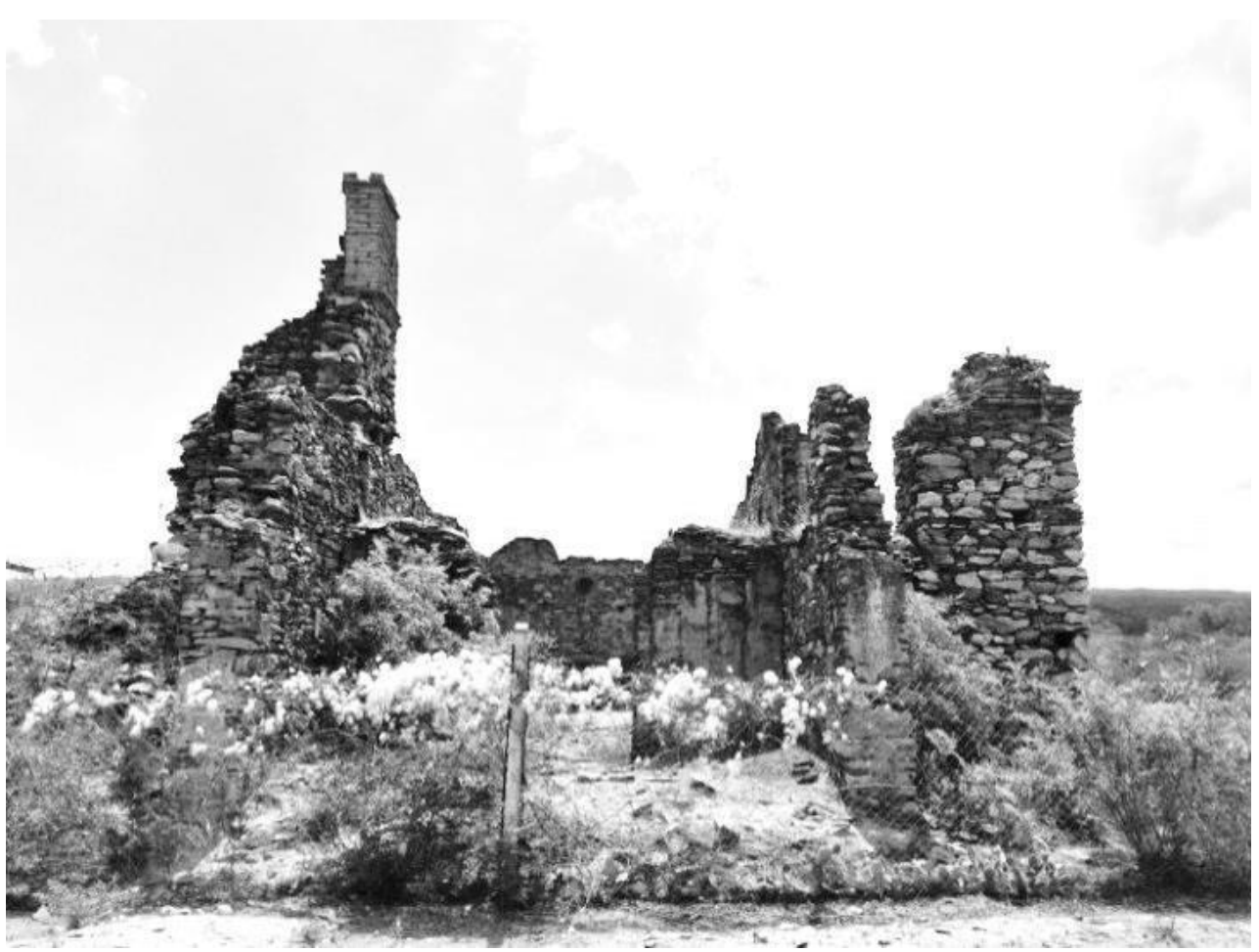

Figura 3: Estado de conservación de la capilla en el año 2014

(Fotografía de los autores)

\section{Sondeos arqueológicos}

Se llevaron a cabo 19 sondeos de $1 \mathrm{x} 1 \mathrm{~m}$, distribuidos como lo muestra la figura $\mathrm{N}^{\circ} 4$. Las profundidades en su mayoría llegaron a los $0,61 \mathrm{~m}$, de forma recurrente en los primeros niveles se halló una gran cantidad de pequeñas concreciones calcáreas, probablemente restos de revoque ya que muestran una superficie pintada con varios colores, como azul y otro blanco sucio, y restos de material cocido (ladrillos). En los subsiguientes niveles se han hallado baldosones enteros sueltos y 
fragmentados, con formas cuadradas y de un tamaño de $0,21 \mathrm{~m}$ de lado y un espesor de $0,35 \mathrm{~m}$, continúan los fragmentos con resto de pintura como en los estratos anteriores.

\begin{tabular}{|c|c|c|}
\hline \multirow{6}{*}{ 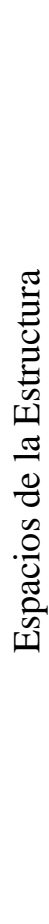 } & I & $\begin{array}{l}\text { Sacristía sus muros están construidos con mampuestos metamórficos } \\
\text { semi-elaborados. La altura del muro es de } 3,5 \mathrm{~m} \text {, sobre éste se apoya } \\
\text { un muro de adobe de unos } 0,70 \mathrm{~m} \text { de alto, el cual coincide con la } \\
\text { parte más alta del techo a un agua }\end{array}$ \\
\hline & II & $\begin{array}{l}\text { La nave central, tiene } 8,5 \mathrm{~m} \text { de ancho por } 16,5 \mathrm{~m} \text { de largo. En el } \\
\text { muro de barro que corona la mampostería de piedra, se pueden ob- } \\
\text { servar elementos de madera de } 0,40 \mathrm{~m} \text { de largo por } 0,35 \mathrm{~m} \text { de alto y } \\
0,30 \mathrm{~m} \text { de lado, que servían de apoyo a las vigas del techo. }\end{array}$ \\
\hline & III & $\begin{array}{l}\text { Sacristía adosada posteriormente a la estructura original; está com- } \\
\text { puesto por un muro de mampuestos metamórficos semi-elaborados y } \\
\text { sobre éste, un muro de abobe con una altura de } 2,3 \text { m en la parte más } \\
\text { alta. }\end{array}$ \\
\hline & IV & $\begin{array}{l}\text { Corresponde al campanario, es el espacio que sufrió más alteracio- } \\
\text { nes y consta de dos plantas: la superior está completamente destrui- } \\
\text { da y la inferior sumamente deteriorada. }\end{array}$ \\
\hline & V & $\begin{array}{l}\text { El atrio del edificio, consta de dos plantas: la superior está comple- } \\
\text { tamente destruida y pertenecía al coro de la Capilla. Posee } 4 \text { pilas- } \\
\text { tras de } 0,3 \mathrm{~m} \text { de ancho, con una separación entre ellas de } 0,25 \mathrm{~m} \text {. }\end{array}$ \\
\hline & VI & $\begin{array}{l}\text { Galería adosada a la nave central. Tiene } 9,45 \mathrm{~m} \text { de largo por } 6,7 \mathrm{~m} \\
\text { de ancho, está tapada por gran cantidad de sedimento el cual será } \\
\text { descrito cuando hablemos de los sondeos realizados. }\end{array}$ \\
\hline
\end{tabular}

Tabla 1: Descripción de los espacios en los cuales se subdividió la Capilla

Se constató la presencia de pintura en esta pared hasta una profundidad de $1 \mathrm{~m}$, la cual presentaba en varios sectores, coloraciones en la gama del azul y crema. Se ha testimoniado la presencia de filas de ladrillos alineados de forma transversal donde finaliza el enlucido y comienza el piso de tierra compactado. En el EIII el final del estrato estuvo dado por la presencia de baldosas en toda la cuadrícula, que conforman el piso de la estructura. Así mismo en el E-VI se halló todo el piso de baldosas, similar al encontrado en la EIII, también se halló una madera que fue interpretada como alfajía que mide $0,77 \mathrm{~m}$ de largo y un espesor de $0,35 \mathrm{~m}$, perteneciente al techo en el cual se puede ver el sector en donde se introducía el clavo en uno de sus extremos, y junto al objeto material de derrumbe talles como baldosas de ladrillo cocido tejas.

En el E-I los sondeos realizados llegaron hasta los $0,93 \mathrm{~m}$ y en los cuales aparte de se recuperar restos de ladrillos y tejas en EI-A exhibía diferencias con respecto a las anteriores en cuanto a la coloración, consolidación y granulometría; presentaba un color gris claro. Es en último estrato apareció la mayor cantidad de hallazgos. Hay tiestos de varios tamaños y lo más llamativo son los fragmentos de vasijas con decoración pintada y engobe (estilo Aguada). 


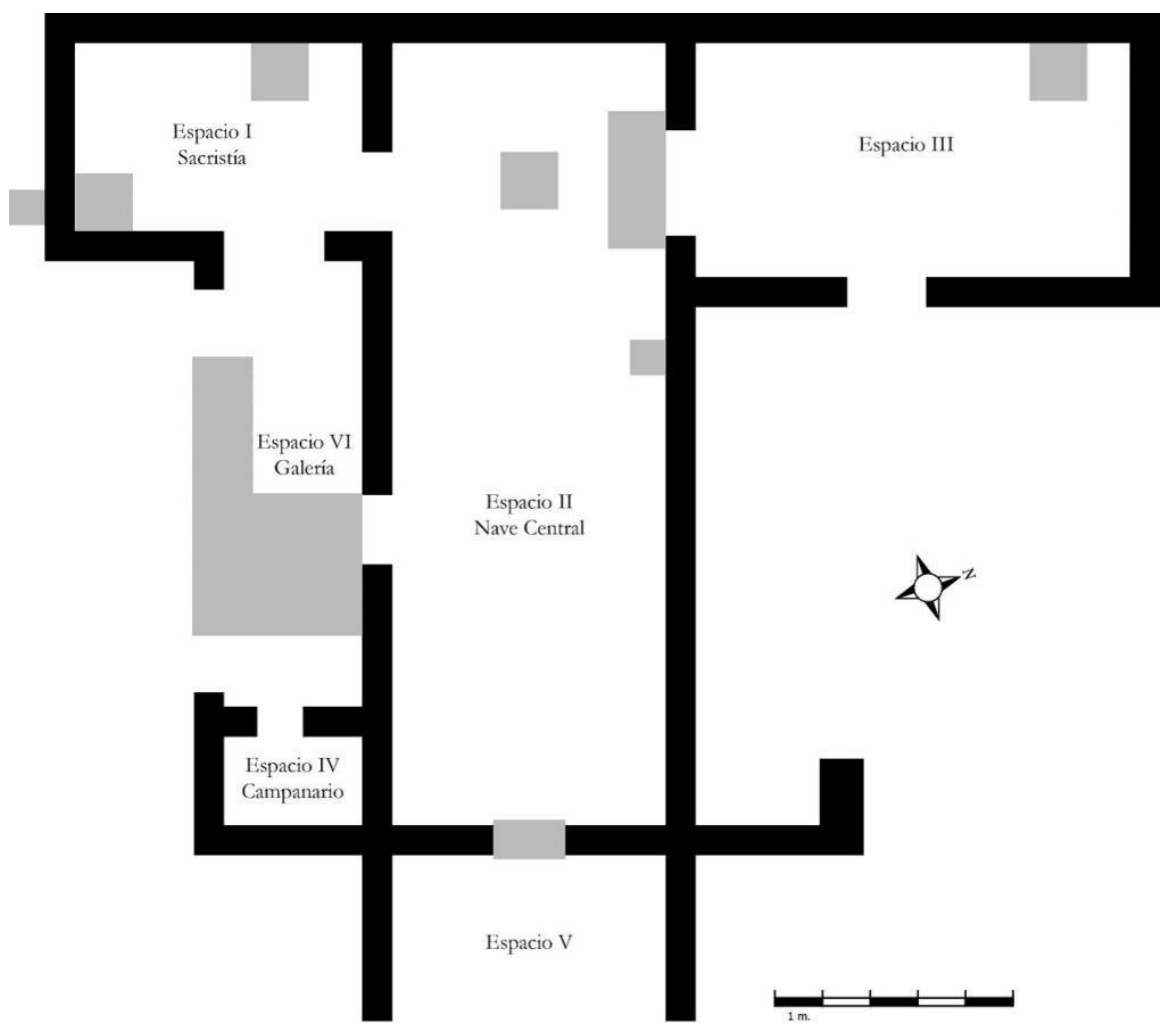

Figura 4: Planimetría de la Capilla de Amadores, muestra los espacios e indica la ubicación de los sondeos

En el EI-B, se halló material cocido, asociado a estos se halló unos clavos de hierro, fragmentos de loza, un cuello de florero, el cual posee una variación de tonos rojos y bordes blancos es un fragmento de florero de tallo alto típico de iglesia o cementerio, realizado en vidrio soplado cuyo estilo se lo denomina Art Nouveau (Schávelzon, comunicación personal) y fragmentos de tela, además un fragmento de espejo pues aún se nota una capa de nitrato de plata, un vidrio traslucido, perteneciente a un fragmento de vidrio y debió haber sido de una ventana o puerta (Schávelzon, comunicación personal).

\section{Consideraciones finales}

Como habíamos planteado al comienzo de esta investigación, nuestro objetivo fue comprender el contexto histórico y cómo fueron los procedimientos de creación, ocupación y transformación de la Capilla de Amadores. En la actualidad se encuentra en ruinas y la población existente la considera como perteneciente a la orden jesuítica, a tal punto que fue declarada monumento histórico provincial. Creemos que a través del abordaje desde la Arqueología Histórica, intentamos presentar una serie de evidencias sobre la vieja Capilla de Amadores, en la cual se 
fundamenta su construcción en el año 1869 y no tienen ninguna relación con los Jesuitas, esto no le resta valor histórico, ya que, conjugamos fuentes históricas de diferentes archivos, como así también incluimos los aportes de la arqueología a través de los diversos sondeos estratigráficos y relevamientos arquitectónicos, donde pudimos determinar la funcionalidad de casi todos los espacios, como así también algunas remodelaciones que nos permitieron acceder a contextos históricos para contribuir a la interpretación de la morfología de su planta, los componentes arquitectónicos de la unidad de análisis y poder explicar las técnicas constructivas, considerando al edificio como un documento histórico. No se halló nada que haga mención a dicha Orden, pero sí pudimos recuperar otros datos valiosos:

- Se determinó la composición de los techos

- Se hallaron los pisos

- Se encontró la galería

- Se registraron tres episodios de pintura en las paredes

- Se identificaron partes de las paredes reconstruidas

La mayoría de los materiales descriptos en los sondeos y los archivos permiten inferir que la capilla de Amadores fue construida en parte, con materiales reciclados de la iglesia que distaba a $12 \mathrm{~km}$ de allí, como pueden haber sido las tejas y tejuelas que formaron parte de los techos. Además se usaron otros materiales en su construcción como piedras, ladrillos y adobe. Esto en parte se cristaliza en las cartas halladas en los archivos y los periódicos de época donde los propietarios (de tierras) son quienes se comunican con las autoridades religiosas y políticas para que se involucren y medien en el traslado de los servicios religiosos de una capilla a la otra.

En relación a los sectores sociales que coexistieron alrededor de la misma fueron religiosos, propietarios y peones; que vinculados en una realidad económica del valle de Paclín, hacia 1869 la localidad fue el eje económico del valle, había varios propietarios que se repartían la tierra y acaparaban las riquezas que se producción, dado que a mediados del siglo se producía algodón y lanas de llamas que alimentaban las industrias que se desarrollaban en la ciudad de Catamarca. Es en esta época donde pasan viajeros y cronistas extranjeros (Burmeister, De Moussy, Mulhall) que detallan los abundantes recursos naturales, como las historias y tradiciones de las distintas poblaciones que visitaron, denotando el interés particular que le prestaron las potencias extranjeras a la riqueza del lugar.

En 1876 se realizó la fundación de la nueva localidad de La Merced ${ }^{6}$ y su declaración como cabecera departamental y asiento de los principales propietarios de tierra del valle. Esto es de vital importancia pues se da una reorganización política y social que afectara a la población del valle en general. A su vez, el peso masivo del librecambio a través de productos principalmente británicos, puso en jaque la economía local que lentamente se volcó a la reprimarización de la tierra, desmantelando consigo las industrias incipientes que alguna vez afloraron en el valle de Catamarca.

Ya promediando el final del siglo XIX, la lana de llama y el algodón son completamente reemplazados por el cultivo de tabaco que se da con éxito en todo 
el valle Paclín. Dándose así las condiciones económicas y políticas que favorecen la aparición de productores como Wilfrido Figueroa, terrateniente de relevancia en el departamento, quién tendrá un rol destacado en la formación de la localidad de La Merced, fundada en 1876, que será con el tiempo, la nueva cabecera departamental y asiento del poder económico local. De esta manera la población que vivió alrededor de esta capilla sufrió un proceso de pobreza generalizado, por la falta de oportunidades y la inestabilidad política que atravesó la última década del XIX y principios del XX, al igual que los habitantes de Amadores, la Capilla corrió la misma suerte, porque hacia 1920 estaba completamente abandonada.

\section{Notas}

1. Ley 5270/09 Los fundamentos dicen que aunque no existen documentos que avale la existencia de la orden jesuítica, se cree que fueron de la congregación por las características constructivas de la iglesia y por estar las ruinas en proximidades a territorios que fueron estancias jesuíticas del siglo XVIII (Diario El Ancasti 04/10/2012).

2. Ellos son Ambato, Piedra Blanca y Paclín.

3. Catamarca fue parte del Obispado de Salta hasta 1909 año de la creación del Obispado de Catamarca.

4. Diario El Creyente (Catamarca) 6 de marzo de 1883 páginas 14-15. Sección Hemeroteca, folio VII, Biblioteca Olmos, Catamarca.

5. Archivo del Obispado Catamarca- Carpeta de Paclín 1885 Protocolo $\mathrm{N}^{\circ} 1$ fs.84.

6. Ley provincial $\mathrm{N}^{\circ} 277$.

\section{Referencias bibliográficas}

ALVERO, L. 2007. Política y poder en el Noroeste Argentino. Una aproximación a la dimensión material de la elite política de Catamarca a inicios del siglo XIX. En: http://nuevomundo.revues.org/ (extraído el 23/04/2014)

ARUEDA J. 1918. Carta al Obispo Bernabé Piedrabuena, Catamarca. Carpeta Paclín. Archivo Del Obispado De Catamarca

BAZÁN, R. 1995. Historia del Noroeste Argentino. Editorial Plus Ultra. Buenos Aires.

CARAFFINI, C. 2014. Análisis comparativo de las parroquias rurales del siglo XIX en el departamento Paclín. Provincia de Catamarca. Tesis de Licenciatura en Arqueología Inédita. Escuela de Arqueología. Universidad Nacional de Catamarca. Catamarca.

CARAFFINI, C; PUENTES, H; FONSECA, E; VILLAFAÑEZ E. Y C, MELIÁN. 2014 "Desarrollo capitalista alrededor de dos capillas rurales del siglo XIX. Depar- 
tamento Paclín, Catamarca". En: IV Simposio Nacional E Internacional "Teoría y Práctica de la Arqueología Histórica Latinoamericana" -Pasado y Futuro de la Arqueología Histórica - Universidad Nacional de Rosario.

PADILLA P. 1885 Carta al gobernador de Catamarca. Carpeta Paclín. Archivo del Obispado de Catamarca

POUCEL, B. 1864. La province de Catamarca En: Bulletin de la Société de Géographie. Libraire De La Société. París Francia

SEGURA J. 1885 Carta al vicario capitular Pablo Padilla. Catamarca. Carpeta Paclín. Archivo del Obispado de Catamarca.

SOSA GALLARDO, S. 1969 Frontones realizados con ático en la arquitectura hispanoamericana. En: Anales del Instituto de Arte Americano e Investigaciones Estéticas. Núm. 22 Impreso en Talleres Gráficos de Domingo Taladríz. Buenos Aires.

TORRES ESCANDELL, J.1914. Catamarca. Carpeta Paclín. Archivo Del Obispado De Catamarca

VILLAFAÑEZ, E.; ACUÑA, G.; FONSECA, E. 2008a. Reinterpretando la Vieja Iglesia de Amadores. En: VI Congreso Argentino de Americanistas: 59-78. Ciudad Autónoma de Buenos Aires.

2008b. Arqueología y arquitectura en la Vieja Iglesia de Amadores. En: 8vas Jornadas de Humanidades. San Fernando del Valle de Catamarca. Catamarca.

VILLAGRÁN M. Y VILLAGRÁN, J. Testamento Y Legado Para La Escuela De Niñas. Expediente 705 bis. Año 1795. Archivo Histórico de Catamarca.

Recibido: 31 de marzo 2016. Aceptado: 4 de octubre 2016. 